\title{
Growing $\mathrm{Cu}_{2} \mathrm{~S}$ Nanoparticles on CdS/ITO Substrates for Photocatalytic Degradation of Methylene Blue
}

\author{
Hongcheng Pan ${ }^{1,2, a}$, Shan Huang ${ }^{1, b}$, and Shaoxian Zhong ${ }^{1, c}$ \\ ${ }^{1}$ College of Chemistry and Bioengineering, Guilin University of Technology, Guilin 541004, P. R. \\ China \\ ${ }^{2}$ Guangxi Colleges and Universities Key Laboratory of Food Safety and Detection, College of \\ Chemistry and Bioengineering, Guilin University of Technology, Guilin 541004, P. R. China \\ aemail: panhongcheng@glut.edu.cn, bemail: 412235337@qq.com, 'email: 364608573@qq.com
}

Keywords: $\mathrm{Cu}_{2} \mathrm{~S}$, CdS, nanoparticles, photocatalysis, methylene blue.

Abstract. CdS thin films were deposited on indium-tin-oxide (ITO) coated glass substrates by a chemical bath deposition method. Then the CdS/ITO slides were immersed in the solution containing $1.6 \mathrm{mM} \mathrm{CuCl}_{2}$ and $1.4 \mathrm{mM}$ cetyltrimethylamonium chloride at $37^{\circ} \mathrm{C}$ for $3 \mathrm{~h}$ to growth $\mathrm{Cu}_{2} \mathrm{~S}$ nanoparticles on the CdS/ITO slides. The scanning electron microscopy (SEM) and X-ray diffraction analysis demonstrated the presence of $\mathrm{Cu}_{2} \mathrm{~S}$ on the surface of $\mathrm{CdS} / \mathrm{ITO}$ slides. The electrochemical behavior of the $\mathrm{Cu}_{2} \mathrm{~S}-\mathrm{CdS} / \mathrm{ITO}$ slide was studied using voltammetric scanning method. The $\mathrm{Cu}_{2} \mathrm{~S}-\mathrm{CdS} / \mathrm{ITO}$ slides exhibited an enhanced photocatalytic efficiency towards the degradation of methylene blue dye under irradiation with a Xenon lamp.

\section{Introduction}

$\mathrm{Cu}_{2} \mathrm{~S}$ is an important semiconductor with a bulk band gap of $1.21 \mathrm{eV}$ and has been extensively investigated and used in a wide variety of fields such as photocatalysts, solar cells and oxygen evolution reaction[1-6]. The availability of $\mathrm{Cu}_{2} \mathrm{~S}$ nanostructures with well-defined morphologies and dimensions should enable new types of applications and/or enhance the performance of currently existing photoelectric devices because of the quantum-size effects.

Recent efforts have focused on the development of new synthetic methodologies for fabricating $\mathrm{Cu}_{2} \mathrm{~S}$ nanocrystals with controlled shape, size, and assembled structure. $\mathrm{Du}$ et al report a facile approach to fabricate hexagonal $\mathrm{Cu}_{2} \mathrm{~S}$ nanocrystals through thermolysis of a copper dithiolate precursor in dodecanethiol[7]. Xie et al. developed a template- and surfactant-free method to synthesize double-fold snowflake $\mathrm{Cu}_{2} \mathrm{~S}$ dendrites[8]. Jiang et al. prepared hierarchically assembled ITO@ $\mathrm{Cu}_{2} \mathrm{~S}$ nanowire arrays with conductive single-crystalline ITO cores and $\mathrm{Cu}_{2} \mathrm{~S}$ nanocrystal shells for solar cell. These arrays not only provided an efficient three-dimensional charge transport network but also allowed for the effective deposition of more $\mathrm{Cu}_{2} \mathrm{~S}$ nanocrystals as active sites to catalyze the electrolyte reaction[9]. Also, copper alkanethiolates have been used as organometallic precursors to form $\mathrm{Cu}_{2} \mathrm{~S}$ nanodisks upon thermal decomposition. This method provides new insights into the use of liquid crystalline phases as templates for nanocrystal synthesis and as a potential route for achieving highly anisotropic inorganic nanostructures[10]. A liquid-state transformation process from hexagonal-phase $\mathrm{CuS}$ nanoparticles was employed to fabricate the cubic-phase $\mathrm{Cu}_{2} \mathrm{~S}$ nanoparticles. The $\mathrm{CuS}$ nanoparticles were converted into $\mathrm{Cu}_{2} \mathrm{~S}$ nanoparticles but maintained the morphology. The $\mathrm{Cu}_{2} \mathrm{~S}$ nanoparticles exhibit better oxygen evolution reaction activity than $\mathrm{CuS}$ nanoparticles[11].

Here we report a simple method to growth $\mathrm{Cu}_{2} \mathrm{~S}$ nanoparticles onto $\mathrm{CdS} / \mathrm{ITO}$ substrates. Scanning electron microscopy (SEM), UV-vis absorption spectra, cyclic voltammetry (CV) and X-ray diffraction (XRD) analyses were carried out to investigate $\mathrm{Cu}_{2} \mathrm{~S}$ and $\mathrm{CdS}$ nanoparticles. We also studied the photocatalytic efficiency of the $\mathrm{Cu}_{2} \mathrm{~S}-\mathrm{CdS} / \mathrm{ITO}$ slides towards the degradation of methylene blue (MB). 


\section{Experimental Section}

Materials. $\mathrm{CdCl}_{2}$ and $\mathrm{Na}_{3}$-citrate were purchased from Longxi chemical (Shantou, China). Thiourea was obtained from Dahao Fine Chemicals (Guangdong, China). Ammonia was from Ailian chemical (Guangdong, China). $\mathrm{CuCl}_{2}$, methylene blue (MB), and cetyltrimethylamonium chloride (CTAC) were obtained from Sinopharm Chemical Reagent (Beijing, China). Other reagents were of analytical grade. Ultrapure water (resistivity $>18 \mathrm{M} \Omega \mathrm{cm}$ ) was obtained from a WP-UP-IV-30 purification system (Woter, China) and used in the all experiments.

Deposition of CdS thin films. CdS thin films were deposited on indium-tin-oxide (ITO) coated glass substrates by chemical bath deposition technique. Films of CdS were deposited from stirred aqueous solutions containing $15 \mathrm{~mL}$ of $5 \mathrm{mM} \mathrm{CdCl}_{2}, 4 \mathrm{~mL}$ of $0.05 \mathrm{M}$ thiourea, $8 \mathrm{~mL}$ of ammonia $(2.5 \%, \mathrm{w} / \mathrm{w}), 5 \mathrm{~mL}$ of $0.05 \mathrm{M} \mathrm{Na}_{3}$-citrate, and $18 \mathrm{~mL}$ ultrapure water. Before the deposition, the ITO substrates were ultrasonically cleaned subsequently in ethanol, acetone, and water, followed by drying in air. The cleaned substrates were immersed in the deposition solution at $83{ }^{\circ} \mathrm{C}$ for $3 \mathrm{~h}$. Then the substrates were removed from the deposition bath, rinsed with ultrapure water, dried in air. After the deposition, yellowish and adherent CdS thin films were observed (hereafter abbreviated as CdS/ITO).

Growth of $\mathbf{C u}_{2} \mathbf{S}$ on CdS/ITO slides. To a $15-\mathrm{mL}$ beaker were sequentially added with $9.85 \mathrm{~mL}$ ultrapure water, $80 \mu \mathrm{L}$ of $0.2 \mathrm{M} \mathrm{CuCl}_{2}, 70 \mu \mathrm{L}$ of $0.2 \mathrm{M} \mathrm{CTAC}$, the total volume of the growth solution being increased to $10 \mathrm{~mL}$ by the addition of ultrapure water. Then the solution was heated to $37^{\circ} \mathrm{C}$ and the CdS/ITO slides were immersed in the solution for $3 \mathrm{~h}$. The slides were then taken out, rinsed with ultrapure water, and dried in air.

SEM, XRD, UV-vis absorption spectra, and electrochemical measurements. The structural properties of the $\mathrm{Cu}_{2} \mathrm{~S}$ and $\mathrm{CdS}$ nanoparticles were studied by scanning electron microscopy (Hitachi FE-SEM S4800, Japan) and XRD (X'pert PRO, Philips, Eindhoven, Netherlands). UV-vis absorption spectra were recorded on a TU-1901 double beam UV-vis Spectrophotometer (Purkinje General, China). CV experiments were carried out on a CHI 660b electrochemical workstation (Ch Instruments, China) with a conventional three-electrode system consisting of a $\mathrm{Ag}_{2} \mathrm{~S} / \mathrm{ZnS} / \mathrm{ITO}$ slide as the working electrode, an $\mathrm{Ag} / \mathrm{AgCl}(3 \mathrm{M} \mathrm{KCl})$ electrode as the reference electrode, and a Pt column electrode as the counter electrode.

\section{Results and discussion}

SEM and XRD. Fig. $1 \mathrm{a}$ and $1 \mathrm{~b}$ show SEM images before and after the growth of $\mathrm{Cu}_{2} \mathrm{~S}$. As can be seen in Fig. 1a, the CdS film consists of densely packed spherical grains with diameters of 70-80 nm. After Growing $\mathrm{Cu}_{2} \mathrm{~S}$, it can be seen that large nanoparticles were grown. The size distribution histogram of the nanoparticles (Fig. 1c) is comprised of two groups of populations, one at about 76 $\mathrm{nm}$, and the other at $142 \mathrm{~nm}$. The first one can be attributed to CdS nanoparticles, which is consistent with the average diameter of about $75 \mathrm{~nm}$ of the deposited CdS nanoparticles (Fig. 1a). We may reasonably conclude that the second one is attributed to grown $\mathrm{Cu}_{2} \mathrm{~S}$ nanoparticles. The XRD study supports our conclusion. The XRD pattern in Fig. 1d shows six peaks located at $21.3^{\circ}, 30.3^{\circ}, 35.2^{\circ}$, $45.4^{\circ}, 50.6^{\circ}$, and $60.3^{\circ}$, whose locations and relative intensities are almost the same as those of $\operatorname{In}_{2} \mathrm{O}_{3}$ with cubic structure (JCPDS 89-4595), except that all peak locations shifted little towards smaller diffraction angles. The shifts of the peak locations should be attributed to the formation of ITO solid solution by doping with $\mathrm{Sn}^{4+}$ at $\mathrm{In}^{3+}$ site in the $\mathrm{In}_{2} \mathrm{O}_{3}$. Apart from the diffraction peaks of ITO, the other peaks all correspond to $\mathrm{Cu}_{2} \mathrm{~S}$ (JCPDS 89-2670). Because the CdS nanoparticles are small and poor crystallinity, we did not observe any discernible peaks of CdS. 

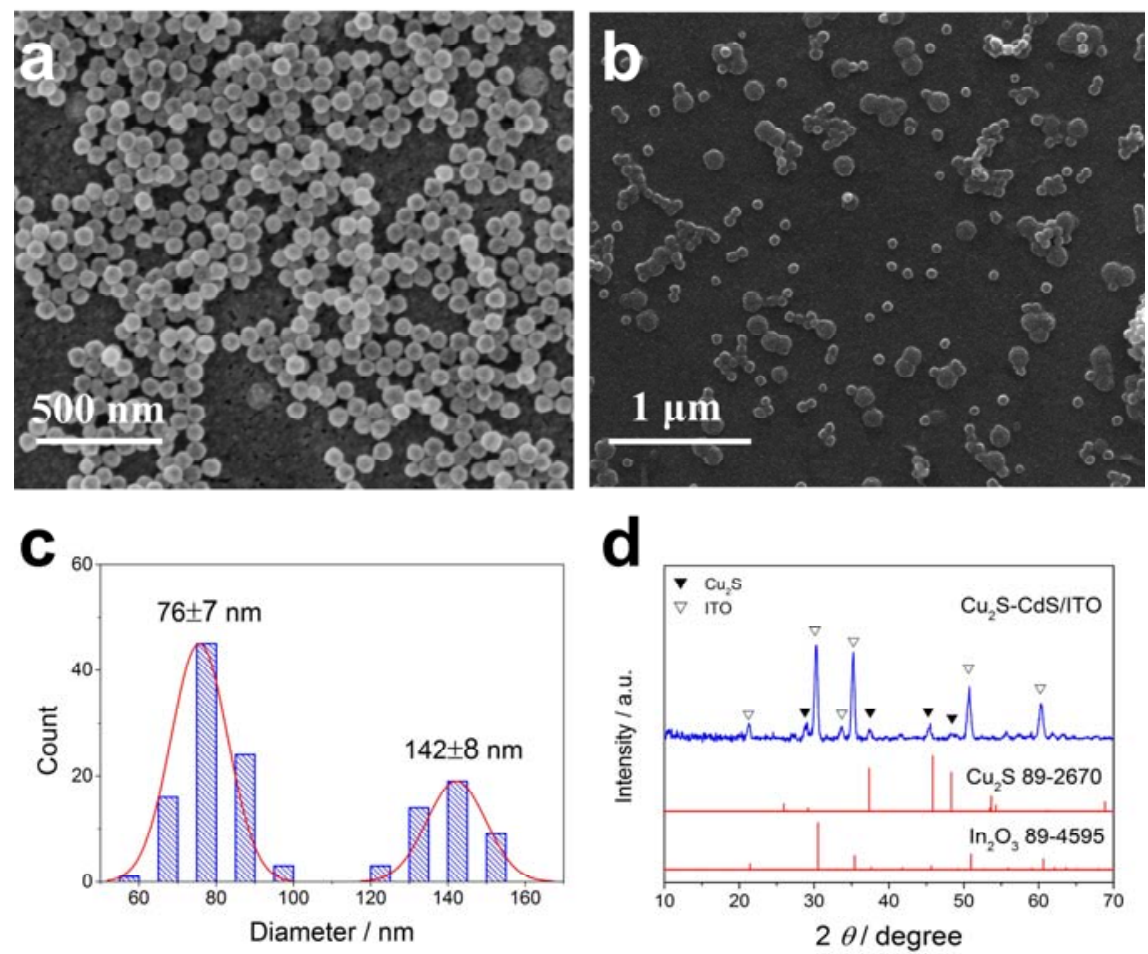

Fig. 1. SEM images of a) before and b) after the growth of $\mathrm{Cu}_{2} \mathrm{~S}$ onto the $\mathrm{CdS} / \mathrm{ITO}$ slide. c) the size distribution histogram. d) XRD of the $\mathrm{Cu}_{2} \mathrm{~S}-\mathrm{CdS} / \mathrm{ITO}$ slide.

Cyclic voltammogram and photocatalytic degradation of MB. Fig. 2a shows the CV of the $\mathrm{Cu}_{2} \mathrm{~S}-\mathrm{CdS} / \mathrm{ITO}$ slide in a solution containing ammonia $(13 \%, \mathrm{w} / \mathrm{w})$ and $0.75 \mathrm{M}\left(\mathrm{NH}_{4}\right)_{2} \mathrm{SO}_{4}$. Two prominent anodic peaks occur. The first one at about $-0.5 \mathrm{~V}$ could be attributed to the reduction: $\mathrm{Cu}_{2} \mathrm{~S}$ $\rightarrow \mathrm{CuS}+\mathrm{Cu}\left(\mathrm{NH}_{3}\right)_{4}{ }^{2+}+2 e^{-}$. The anodic peak at $-0.1 \mathrm{~V}$ could be attributed to the reduction: $\mathrm{CuS}+$ $8 \mathrm{OH}^{-} \rightarrow \mathrm{Cu}\left(\mathrm{NH}_{3}\right)_{4}{ }^{2+}+\mathrm{SO}_{4}{ }^{2-}+8 e^{-}$. The electrochemical analysis is consistent with the results of SEM and XRD, supporting that $\mathrm{Cu}_{2} \mathrm{~S}$ nanoparticles are formed.

Fig. 2a show the UV-vis absorption spectra of an aqueous solution of $0.025 \mathrm{mM} \mathrm{MB}$ with a $\mathrm{Cu}_{2} \mathrm{~S}-\mathrm{CdS} / \mathrm{ITO}$ slide after irradiation with a 300-W Xenon lamp for different durations of time. The characteristic absorption peak of MB at $664 \mathrm{~nm}$ is monitored as a function of the light exposure time. It can be seen that the absorption peak at $664 \mathrm{~nm}$ diminishes sharply after $10 \mathrm{~min}$ of irradiation and almost completely disappears after $40 \mathrm{~min}$ of irradiation. No new absorption peaks appear in the $\mathrm{UV}$-vis region, which clearly indicates the complete photocatalytic degradation of MB. It must be pointed out here that an adsorption of $\mathrm{MB}$ onto the $\mathrm{Cu}_{2} \mathrm{~S}-\mathrm{CdS} / \mathrm{ITO}$ slide in dark prior to light exposure did not result in any significant change in the absorption spectrum of MB.
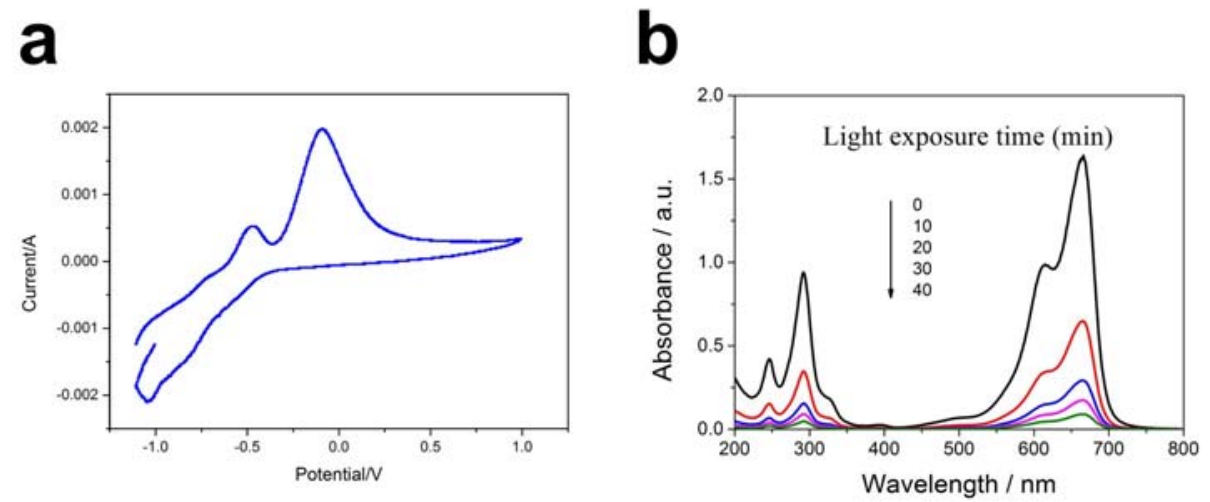

Fig. 2 a) $\mathrm{CV}$ of $\mathrm{CV}$ of the $\mathrm{Cu}_{2} \mathrm{~S}-\mathrm{CdS} / \mathrm{ITO}$ slide in a solution containing ammonia $(13 \%, \mathrm{w} / \mathrm{w})$ and $0.75 \mathrm{M}\left(\mathrm{NH}_{4}\right)_{2} \mathrm{SO}_{4}$. b) UV-vis absorption spectra showing temporal evolution of photocatalytic degradation of $\mathrm{MB}$ upon irradiation with a 300-W Xenon lamp. 


\section{Conclusions}

In this study, we have synthesized $\mathrm{Cu}_{2} \mathrm{~S}-\mathrm{CdS}$ nanoparticles on the ITO slides by using a facile wet chemical method. The structural, electrochemical, and photocatalytic properties of $\mathrm{Cu}_{2} \mathrm{~S}-\mathrm{CdS} / \mathrm{ITO}$ slides have been investigated. The CdS film consists of densely packed spherical grains with diameters of $70-80 \mathrm{~nm}$. After the CdS/ITO slides were immersed into a solution containing $\mathrm{CuCl}_{2}$ and CTAC, large $\mathrm{Cu}_{2} \mathrm{~S}$ nanoparticles (about $140 \mathrm{~nm}$ in diameter) were grown near the $\mathrm{CdS}$ nanoparticles. The electrochemical behavior of the $\mathrm{Cu}_{2} \mathrm{~S}-\mathrm{CdS} / \mathrm{ITO}$ slide was studied using voltammetric scanning method. The $\mathrm{Cu}_{2} \mathrm{~S}-\mathrm{CdS} / \mathrm{ITO}$ slides exhibited an enhanced photocatalytic efficiency towards the degradation of methylene blue dye under irradiation with a Xenon lamp.

\section{Acknowledgements}

This work was financially supported by National Natural Science Foundation of China (20905016, 21265005) and Guangxi Natural Science Foundation (0991082).

\section{References}

[1] S.C. Riha, R.D. Schaller, D.J. Gosztola, G.P. Wiederrecht, A.B.F. Martinson: J. Phys. Chem. Lett., Vol. 5 (2014), p. 4055

[2] Y. Jiang, X. Zhang, Q. Ge, B.-B. Yu, Y. Zou, W. Jiang, W. Song, L. Wan, J. Hu: Nano Lett., Vol. 14 (2014), p. 365

[3] S.C. Riha, S. Jin, S.V. Baryshev, E. Thimsen, G.P. Wiederrecht, A.B.F. Martinson: ACS Appl. Mater. Inter., Vol. 5 (2013), p. 10302

[4] Z. Zhuang, Q. Peng, B. Zhang, Y. Li: J. Am. Chem. Soc., Vol. 130 (2008), p. 10482

[5] J.-F. Zhu, Y.-J. Zhu, M.-G. Ma, L.-X. Yang, L. Gao: J. Phys. Chem. C, Vol. 111 (2007), p. 3920

[6] Z. Liu, D. Xu, J. Liang, J. Shen, S. Zhang, Y. Qian: J. Phys. Chem. B, Vol. 109 (2005), p. 10699

[7] X. Du, Z. Yu, A. Dasari, J. Ma, Y. Meng, Y. Mai: Chem. Mater., Vol. 18 (2006), p. 5156

[8] Z. Wu, C. Pan, Z. Yao, Q. Zhao, Y. Xie: Cryst. Growth Des., Vol. 6 (2006), p. 1717

[9] Y. Jiang, B.-B. Yu, J. Liu, Z.-H. Li, J.-K. Sun, X.-H. Zhong, J.-S. Hu, W.-G. Song, L.-J. Wan: Nano Lett., Vol. 15 (2015), p. 3088

[10] W. Bryks, M. Wette, N. Velez, S.-W. Hsu, A.R. Tao: J. Am. Chem. Soc., Vol. 136 (2014), p. 6175

[11] L. An, P. Zhou, J. Yin, H. Liu, F. Chen, H. Liu, Y. Du, P. Xi: Inorg. Chem., Vol. 54 (2015), p. 3281 